\title{
Business Environment Constraints and Measures of Private Enterprises in Beijing-Tianjin-Hebei
}

\author{
Hong-yin Liu \\ Tianjin Agricultural University \\ NO.22, Jinjing Road, Tianjin, P.R.China, \\ lhy813@163.com
}

\begin{abstract}
The close but unclear relationship between the government and business undermines the honesty and fair competition in the government-business ecology. This research makes a field survey on the business environment of the representative private enterprises in Beijing, Tianjin and Hebei by in-depth interview. The survey reveals some problems, for example the efficiency of government service has not been greatly improved after the "Decentralization-Control-Service" reform, the three-door phenomenon of private enterprises still exists, the financing difficulties are serious, the structure of talent policy is unreasonable, and some policies have not been well promoted and so on. These problems suppress the vitality of the private economy. It is suggested to carry out inventory assessment including positive list and negative list, to construct the probusiness, pro-people public organization culture, to strengthen the performance appraisal of civil servants, to improve the sharing of credit system and property rights pledge system, to play the financing guarantee of chambers of Commerce and associations, to establish the service policy for small and micro enterprises, and to implement special support policies for hightech talent in private enterprises.
\end{abstract}

Keywords-Private enterprises; Business environment; BeijingTianjin-Hebei; Government-business relationship

\section{INTRODUCTION}

To play the basic role of the market in the allocation of resources needs to respect and realize the principal status of the private enterprises in the market. How to realize the equal competition between the private enterprises and the stateowned enterprises and their integration and development is a difficult problem to be solved in the reform of the state-owned enterprises. Compared with the southern provinces, the development of the private economy in the north is slow, with private enterprises only $48 \%$, the tax contribution $44 \%$, while the private enterprises in the South reach $70 \%$ with the tax revenue $80 \%$, and the employment $90 \%$. To solve the problem of development of private enterprises under the new normal, Nankai University and government departments constitute a joint investigation team on the business environment of private enterprises in Beijing-Tianjin-Hebei. The survey found that the business environment of Beijing, Tianjin and Hebei restrained the vitality of private enterprises and is not conducive for the sustainable and healthy development of private enterprises.

\section{MUlTIPLE CONSTRAINTS IN THE DEVELOPMENT OF PRIVATE ENTERPRISES IN BEIJING, TIANJIN AND HEBEI}

\section{A. The efficiency of government service has not been greatly improved after the "Decentralization-Control-Service" reform and being difficult to form the close and clean government-business relationship}

First, there is a lack of a clear list of submissions in the administrative examination and approval. After the reform, the level of the administrative examination and approval service has not been improved, but the examination and approval procedure of each department is still the same after 109 seals become one. The approving department did not publish the detailed list of Requisites in time, and did not publish the differentiating audit details of different approvals. Instead, it proposed adding materials randomly, which led to more errands for enterprises. In fact, the required documents are clearly listed in the US administrative examination and approval, and audit is passed by one-time.

Second, civil servants dare not bear responsibility, but implement the policy dogmatically. Even detailed policy provisions are difficult to cover all kinds of individual conditions, thus policy provisions only define guiding ideology, policy spirit and general principles. In accordance with the principle of "entry without prohibition ", the policy executor should have certain space for free discretion. However, in practice, the policy implementation personnel are not willing nor dare to bear responsibility, thus distort policy connotation and reduce the effect of policy implementation.

Third, a harmonious relationship between the government and the business has not been established. The development of private enterprises cannot be separated from the support of the government, but the public servants may be alienated from the enterprises for "clear", or are accused of "close". The government should formulate a positive list of "close" and a negative list of "clear", to form the close and clean government-business relationship that is in line with China's national conditions, by releasing public servants' hands and feet to boldly serve the civil and commercial sectors.

Fourth, the frequent mobilization of government leaders is not conducive to the stability of government-business relationship. The frequent mobilization of the leadership of the party and government affects the sustainability, cohesion and 
stability of the government's services. It takes time for leaders to be familiar with enterprises or enterprises' communication with governments, so the frequent mobilization of leaders is not conducive to the construction of a stable government and business ecology.

\section{B. The three-door phenomenon and unfair treatment of the private enterprises still exist}

Compared with the unit within the system, three doors ("glass door", "spring door", and "revolving door") of the enterprises outside the system are serious [1].

First, the "glass door" phenomenon is difficult to eradicate. Although the government has formulated a series of policies which are applied jointly by the internal and external units, the private enterprises still encounter hidden barriers in the process of policy implementation. For example, financial institutions set a higher threshold and more complex procedures for private enterprises, which impede the financing of private enterprises.

Second, institutional discrimination still exists. The reform of China's marketization is on the way, and the policy systems with differences between the internal and external units still exist. For example, in the market access, private enterprises still encounter institutional and policy barriers, and there is a hidden barrier [2] to restrict and limit the development of the external economy.

Third, it is the "revolving door" phenomenon. After the "Decentralization-Control-Service" reform, the service attitude of the government staff has been improved, but the problems still remain. Private enterprises are still not able to solve the problem in time, and the enterprises encounter "revolving door".

\section{Insufficient innovation of financial products and the financing difficulties of private enterprises}

First, banks and other financial institutions do not relax money market for the private enterprise, and the state-owned enterprises are still the main target of lending. Some stateowned enterprises every year lend to private enterprises the unused loan at $12-15 \%$ interest rates. In 2017, the bank tightened up monetary policy, and the amount of loans approved to private enterprises was difficult to be realized.

Second, the private enterprises with light assets have few mortgages, and it is difficult to finance under the condition that the enterprise credit system is not perfect.

Third, for agricultural enterprises, the vegetable greenhouse and so on cannot be mortgaged, and land property rights certificate cannot be used for mortgage loan (not approved by banks). In some provinces and cities the Financial Bureau and the Agricultural Commission set up a United Guaranty Corporation, but the amount of the guarantee is low and the guarantee fee is high so the agricultural enterprises do not gain much benefit.

Fourth, the free mortgage loan for government procurement project encountered obstacles. According to the regulation, the bank gives $50-80 \%$ of loans to the government procurement project without mortgage, but most private enterprises are hard to reach the threshold of government procurement. Even if the bid is successful, it is difficult for them to get loans due to incomplete government procurement procedures.

\section{Lack of service policy for small and micro enterprises and it is hard to succeed without support for small and micro businesses.}

Private enterprises are mostly MSMEs, which are active and promising market subjects and they need government help to grow. Provincial governments such as Hainan province, Chongqing city and Hubei province provide government procurement services for small and medium-sized enterprises, and the government pays for them as long as they sign marketoriented service contracts. However, there is no relevant policy on micro-enterprise services in Beijing, Tianjin and Hebei, whether financial services or support, where micro-enterprises do not benefit much.

\section{E. Unreasonable personnel policy structure and lack of competitiveness in private enterprises}

First, the internal and external employment policies vary greatly. Units within the system have higher housing Provident fund and housing subsidies, and the pay of employees is generally higher, while private enterprises cannot afford such high costs, so talent competitiveness is naturally low [3] .

Second, the talent policy values the introduction of talents but cares less about the original talents. Discriminatory policies cause unfairness between the internal and external talents and affect the internal talents' enthusiasm. Similarly, the policy of attracting investment places emphasis on the nonlocal enterprises but not the local enterprises, resulting in slow landing of local enterprises.

Third, there is a lack of science and technology service personnel related policies. Most provinces and municipalities in Beijing-Tianjin-Hebei do not have science and technology service personnel policy. According to statistics, the ratio of R\&D talent and pilot talent in the world is $1: 8$, but in China it is $1: 1$, so the construction of advanced manufacturing $R \& D$ base in China needs to train a large number of service talent to transform scientific and technological achievements. This kind of talented person is the short board, and the introduction and cultivation of this kind of talented person needs support from preferential policies. Fourth, personnel tax burden in the hightech private enterprise is heavy. The high income of top talents leads to high individual tax naturally, thus tax policy results in the unfair punishment of "whipping the fast and hard-working". 


\section{F. Inadequate policy promotion, inconsistent standards and poor communication channels for government and business information}

First, policy openness and transparency are insufficient. After policy formulation in Beijing-Tianjin-Hebei there is no timely promotion (compared with Beijing, Tianjin policy promotion is the weaker), thus policy objects do not get policy content in time, and miss the opportunity to enjoy the dividend policy. Private enterprises do not have the ability to set up policy research institutions and specialized personnel, so it needs to set up government information docking platform. The new policy should not only be widely publicized, but also be targeted (such as the policy of attracting investment) to guarantee that the policy can reach the private enterprises.

Second, there are different standards for policy implementation. It is sometimes difficult to implement the same policies and to enjoy the same treatment between local enterprises and those investment enterprises.

\section{SUGGESTIONS FOR IMPROVING THE BUSINESS ENVIRONMENT OF PRIVATE ENTERPRISES}

A. To refine policy provisions, construct the pro-business, pro-people public organization culture, assess the checklist including the positive list and negative list, and explore the implementation of a performance appraisal system for civil servants

First, we should construct the pro-business, pro-people public organization culture to guide the cadres at all levels to change the concept of service. We should make full use of mass media to publicize typical deeds to serve the people, so award nomination and excellence production should be closely related with the efficiency of work in all government units. We should combine the construction of public organization culture with the "two learning and one activity" activities of Party members, and give priority to Party members and cadres to become leaders and promoters of people's business culture. Any behavior of civil servants buck passing problems and making difficulties for people or businessmen should be regarded as nonfeasance and punished by discipline inspection and supervision departments.

Second, the administrative examination and approval department, according to the laws and regulations, the spirit of the Central Committee of the Party and the State Council, formulate the audit checklist, clarify the details of different types of approval documents, and strive for one-time audit.

Third, establish a positive list and a negative list of civil and commercial services. The positive list is the responsibility of the civil servants, and the negative list is to define the bottom line.

Fourth, explore the implementation of the civil service performance assessment system. Formulate and implement the performance appraisal system at all levels, highlight the assessment of administrative efficiency and service performance, and link the results with the salary and promotion of civil servants.

Fifth, establish the direct platform between the government departments and private enterprises, to make sure that government policies passed to the enterprises and opinion of the people known by the government, so as to build a harmonious relationship between the government and business.

\section{B. To play the financing guarantee of chambers of Commerce and associations, improve the sharing of the credit system and property rights pledge system, and broaden the channels of credit financing for private enterprises}

First, establish an interconnected and shared credit system. Improve the existing personal credit and enterprise credit system, to realize the city and country network of credit information, and to ensure the interconnection and sharing of the credit system.

Second, explore the financing methods of implementing credit and joint guarantee of private enterprises of light assets. Banks and other financial institutions carry out joint guarantee loan management methods based on corporate credit and entrepreneur credit rating, chamber of Commerce or association guarantee, Municipal Finance Bureau and administrative department limited liability guarantee, to innovate financial products for light assets enterprises.

Third, improve the financing system of intellectual property pledge. It is suggested that a scientific and technological Guarantee corporation should be set up to ensure that small and medium-sized enterprises in science and technology are mortgaged with patent, trademark, accounts receivable and other property securities. The government incorporate the technology Guarantee Corporation and the commercial banks in the pledge loan business into the patent pledge compensation fund, and determine the risk level according to the risk of the guarantee risk and the risk of the realization of the patent right, so as to determine the risk compensation standard.

Fourth, implement land property rights pledge financing. Banks and other financial institutions speed up the development of land contracting rights and land management warrants financing methods, and explore the rural steel frame shed and other real estate mortgage financing methods. 
C. To improve the infrastructure construction of BeijingTianjin-Hebei, improve educational and medical service institutions, improve the population gathering capacity of Tianjin and Hebei, formulate preferential policies for talents, and improve the competitiveness of private enterprises

First, improve the infrastructure construction of each functional area of Beijing, Tianjin and Hebei, and improve the functions of the development zones and high and new zones. Strengthen the construction of urban public service facilities, such as accommodation, catering, transportation, housing lease, and so on, to build an ecologically livable city and improve the capacity of population aggregation.

Second, establish preferential policies for top talents in private enterprises, such as lowering individual income tax, implementing special care policy for children's schooling, improving pre-school education, basic education and community health service institutions, and promoting the quality of education and medical services.

Third, expand the apartment construction for blue collar and white-collar. In particular, the construction of various low rent Town Apartments facing different classes of private enterprises ensures the housing demand of the employees of private enterprises.

\section{To establish the service policy for small and medium} enterprises, increase the support of government procurement to private enterprises and promote the vitality of private enterprises

First, we should draw on the practice of other areas to establish the service policy for small and medium enterprises. In order to reduce the operation cost of small and mediumsized and micro enterprises, the service mode of "enterprise demand, market produce, and government pay" is adopted. Second, in government procurement, we should develop directional bidding projects for small and medium-sized enterprises, especially for small technology giants, so as to reduce access threshold and enhance competitiveness of small and micro businesses.

\section{CONCLUSION}

After the "Decentralization-Control-Service" reform, the quality of public service supply is different between the internal and external units of the System, and there are still "glass door", "spring door" and "revolving door" phenomena. The business environment is not conducive to the sustainable, rapid and healthy development of private enterprises. How to build a new close and clear government-business relationship with principles needs to deepen the "Decentralization-ControlService" reform, to assess the checklist including the positive list and negative list, to construct the pro-business, pro-people public organization culture, to strengthen the performance appraisal of civil servants, and to achieve a clean and fair administration.

\section{ACKNOWLEDGMENTS}

Liu Hongyin (1968- ), male, Han, Changyi, Shandong Province, Doctor of economics, Professor of humanities, Tianjin Agricultural University. Research area: Human Resource Economics, rural urbanization. E-mail: 1hy813@163.com phone: 15022239716

Address: College of Humanities, Tianjin Agricultural University, No. 22, Jinjing Road, Xiqing District, Xiqing, Tianjin, 300384

This research was financially supported by Tianjin Science and Technology Development Strategy Research Plan in 2017 (17ZLZDZF00510) "Research on the construction of advanced manufacturing $\mathrm{R} \& \mathrm{D}$ base under the background of coordinated development of Beijing, Tianjin and Hebei"; Tianjin University Innovation Team Training Plan (TD135093).

\section{REFERENCES}

[1] Li Xia, Bian Jing. Countermeasures to further optimize the business environment of private enterprises in Hebei province [J]. Journal of the Socialist College of Hebei Province, 2017, (1): 26-29.

[2] Cheng Chunsheng. Suggestions on business environment optimization[J] Cooperation of economy and technology, 2018, (1): 136-137.

[3] Xia Maosen. The development status, existing problems and supporting policies of Shenyang private enterprises[R]. Symposium of the fourteenth annual Scientific and Academic conference in Shenyang(Social science and management), 2017. 